\title{
SMALL ARTHROPODS AS POLLINATORS IN A NEW ZEALAND PAK CHOI FIELD TRIAL
}

\author{
M.K. WALKER, B.G. HOWLETT, J.A. MCCALLUM, A.R. WALLACE \\ and D.A.J. TEULON
}
The New Zealand Institute for Plant \& Food Research Limited, Private Bag 4704, Christchurch, New Zealand

Corresponding author: walkerm@crop.cri.nz

\begin{abstract}
Brassica seed crops are grown throughout New Zealand and worldwide, and inter-crop and crop-weed contamination through gene flow is a major concern. For Brassica, large arthropods (body length $>3 \mathrm{~mm}$ ), particularly honey bees, are the most important pollinators and are considered key vectors of pollen. Small arthropods (body length $<3 \mathrm{~mm}$ ) are also abundant in Brassica crops but their role as pollinators is rarely assessed. Numerous small arthropods (particularly Diptera and Thysanoptera) were recorded within cages surrounding pak choi inflorescences that excluded large arthropods. Inflorescences inside these cages set seed, but seed set was significantly reduced compared with inflorescences in cages that were hand pollinated and uncaged inflorescences. Although the presence of large arthropods significantly increased seed set, the role of small arthropods and wind cannot be excluded in pak choi pollination. Further studies are required to fully determine the role of small arthropods in long distance pollen flow. Keywords: Brassica, pollination, pollen movement, small arthropods, exclusion cage, thrips.
\end{abstract}

\section{INTRODUCTION}

Large arthropods, particularly Hymenoptera (e.g. Apis mellifera) and Diptera (e.g. Syrphidae and Calliphoridae) are considered to be the most important pollinators of Brassica crops (Westerkampe \& Gottsberger 2000; Cunningham et al. 2002) and therefore have been the focus for studies into pollen movement of genetically modified crops (Pierre \& Renard 1999; Cresswell \& Osborne 2004). However, these studies often ignore the role of small arthropods (body length $<3 \mathrm{~mm}$ ), which can represent a large proportion of the flower visitor assemblage (e.g. Diptera from the families Drosophilidae and Ephydridae; and thrips (Thysanoptera)) (Veer 1978; Rubin-Reyes \& Cervancia 1999; Howlett et al. 2009a,b). Understanding the role of small arthropods in pollination of crops such as brassicas is essential to evaluate whether they provide any significant economic value as pollinators (i.e. their relative contribution to seed set) and to assess whether they are likely to provide a significant contribution to unwanted pollen movement from crops.

The objective of this research was to differentiate the contribution of large arthropods versus small arthropods and wind in pak choi (Brassica rapa L. ssp. chinensis L. Hanelt.) pollination. An exclusion cage experiment was used to compare seed set in inflorescences exposed to all arthropods with inflorescences that were only accessible to small arthropods.

\section{MATERIALS AND METHODS}

\section{Exclusion of large arthropods from pak choi inflorescences}

Cages were designed to exclude large arthropods from individual pak choi inflorescences, and were also tested for inhibition of small arthropod access to inflorescences. Experiments were conducted in a single pak choi trial plot $(50 \mathrm{~m} \times 50 \mathrm{~m})$ near Gore $\left(46^{\circ} 06^{\prime} 51.77^{\prime \prime} \mathrm{S}\right.$, 
$\left.168^{\circ} 54^{\prime} 51.90^{\prime \prime} \mathrm{E}\right)$. Cages consisted of a clear acetate plastic (1 $\mathrm{mm}$ thick) cylindrical support covered by a mesh bag (mesh hole size $3 \mathrm{~mm}$ in diameter) that contained a Velcro $^{\circledR}$ opening at the top (Fig. 1). Three green plastic and metal supporting stakes (height $1.5 \mathrm{~m}$, diameter $15 \mathrm{~mm}$ ), were spaced equidistantly around the inflorescence, the cage structure placed over the inflorescence and secured to each stake using Velcro ${ }^{\circledR}$ tags sown to the bag (Fig. 1). The bag was then tied around the inflorescence stem using string to close the cage.

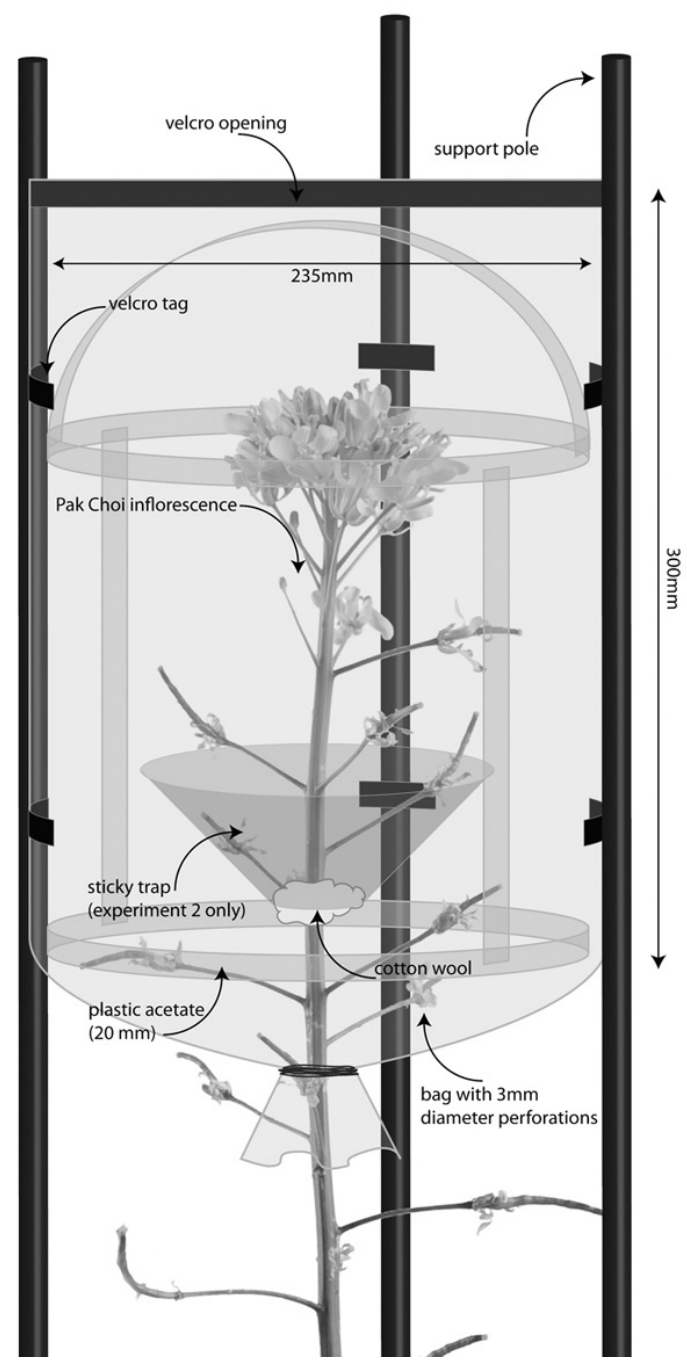

FIGURE 1: Cage designed to exclude large arthropods from pak choi inflorescences. Sticky traps to measure the type and abundance of arthropods were used in Experiment 2 only. 


\section{Experiment 1}

Four $3 \times 3$ Latin squares were laid out in separate blocks. There were three replicates of three treatments per block, giving a total of 12 replicates per treatment. The treatments were: (1) inflorescence enclosed in a cage, allowing the passage of small arthropods only, (2) inflorescence enclosed in a cage, allowing the passage of small arthropods only and with hand cross-pollination (inflorescences were hand pollinated twice daily for 5 days) and (3) uncaged inflorescences. One primary flowering inflorescence containing 25-35 unopened buds that had just begun flowering (i.e. each contained between one and five open flowers) was chosen for each treatment and replicate, and open flowers were subsequently removed. The four blocks were located in each corner of the field, beginning $5 \mathrm{~m}$ inside the two field margins, with treatments and replicates spaced $5 \mathrm{~m}$ apart. Treatments remained in the field until seed set (approximately 3 weeks). For each inflorescence the total number of pods, fully developed (developed to full seed size) and aborted seeds was obtained. The percentage seed set was calculated from the total number of fully developed seeds in all pods and total number of seeds in all pods (fully developed + aborted) in each inflorescence, in order to weight the means appropriately for the variable number of pods per inflorescence. The mean number of fully developed seeds per pod was estimated in the same way.

Data were analysed by ANOVA of angular transformed percentage seed set and $\log$-transformed $\left(\log _{10}(n+1)\right)$ mean number of fully developed seeds per pod and pods per inflorescence using the GenStat statistical package.

\section{Experiment 2}

Sticky traps were used to assess the type and abundance of small arthropod flower visitors inside and outside the cages. The traps consisted of a circular piece of clear acetate, with a central hole (diameter $15 \mathrm{~mm}$ ). It was stapled around the inflorescence stem to form a funnel positioned within $15 \mathrm{~mm}$ of the base of the inflorescence, with cotton wool placed between the stem wall and the acetate to protect the inflorescence stem from damage (Fig. 1). A thin layer of Tangle-Trap ${ }^{\circledR}$ (Insect Trap Coating: paste formula, The Tanglefoot ${ }^{\circledR}$ Company, Michigan USA) was then applied to the acetate to capture arthropods.

The experiment was conducted simultaneously with Experiment 1 and within the same field. Four $2 \times 2$ Latin squares were laid out in two blocks, so the two treatments were replicated eight times (four replicates per block). The treatments were: (1) caged inflorescences containing a sticky trap and (2) open-pollinated inflorescences containing a sticky trap, as a control. The two blocks were located at opposite ends of the field ( $5 \mathrm{~m}$ inside the field margin) spaced equidistantly $(7.5 \mathrm{~m})$ between Experiment 1 blocks, with treatments and replicates spaced $5 \mathrm{~m}$ apart. Experiments 1 and 2, which ran simultaneously, together occupied approximately $62 \%$ of the total field area. Traps were removed from the field after seed set (approximately 3 weeks). Arthropods adhering to the traps were sorted to order or family level where possible and counted.

For arthropod counts, numbers per trap were generally low, so a generalised linear model with Poisson error distribution and log link was used for analysis. Where replicate differences were small and their deviance less than the residual deviance $(\mathrm{P}>0.4)$ the replicate deviance was pooled with the residual (Bancroft \& Han 1983). If the residual deviance was less than the theoretical Poisson value of 1.0 the latter was used to test the difference between treatments. Percentage seed set and mean number of fully developed seeds per pod were calculated as for Experiment 1. Angular transformed percentage seed set and $\log$-transformed $\left(\log _{10}(n+1)\right)$ mean number of fully developed seeds per pod and pods per inflorescence were compared between treatments and between corresponding treatments in the first experiment (i.e. open-pollinated and bagged inflorescences without sticky traps) by ANOVA. 


\section{RESULTS}

For Experiment 1 percentage seed set, mean number of fully developed seeds per pod and pods per inflorescence were all similar for uncaged and hand-pollinated caged inflorescences but were significantly $(\mathrm{P}<0.01)$ less for the caged (no hand pollination) inflorescences (Table 1).

For Experiment 2 percentage seed set for the caged inflorescences was not significantly different to uncaged inflorescences (Table 1). However, the mean number of fully developed seeds per pod was significantly lower for caged inflorescences than for uncaged inflorescences. There was no significant difference in pods per inflorescence between caged and uncaged inflorescences.

Comparing Experiment 2 (sticky traps present) with Experiment 1 (no sticky traps present), there were no significant differences in either percentage seed set for the caged inflorescences or the mean number of fully developed seeds per pod for the uncaged inflorescences (Table 1). However, there were significant differences $(\mathrm{P}<0.05)$ in percentage seed set for the uncaged inflorescences, mean number of fully developed seeds per pod for the caged inflorescences and pods per inflorescence for both caged and uncaged inflorescences.

TABLE 1: Percentage seed set, mean number of fully developed seeds per pod and pods per inflorescence (transformed data in parentheses) for Experiments 1 and 2. T-value is for comparison between the same treatments in Experiments 1 and 2.

\begin{tabular}{lrrr}
\hline & \% seed set & Full developed seeds & Pods/inflorescence \\
\hline Experiment 1 & & & \\
Uncaged control & $70.9(58.2)$ & $12.0(1.08)$ & $23.7(1.30)$ \\
Caged + pollination & $64.4(53.8)$ & $11.8(1.06)$ & $18.3(1.22)$ \\
Caged only & $33.0(34.9)$ & $2.9(0.58)$ & $8.3(0.95)$ \\
LSD 5\% (14 df) & $(8.39)$ & $(0.105)$ & $(0.197)$ \\
\hline Experiment 2 & & & \\
Uncaged control & $41.9(40.1)$ & $5.4(0.97)$ & $7.4(0.88)$ \\
Caged only & $33.5(35.1)$ & $(0.21)$ & $(0.29)$ \\
LSD 5\% (6 or 7 df) & $(7.43)$ & & \\
t-values & & & \\
Uncaged control & $5.2,19.5 \mathrm{df}, \mathrm{P}<0.001$ & $1.62,10.1 \mathrm{df}, \mathrm{P}>0.05$ & $3.87,14.6 \mathrm{df}, \mathrm{P}<0.01$ \\
Caged only & $0.06,19.5 \mathrm{df}, \mathrm{P}>0.05$ & $2.46,10.1 \mathrm{df}, \mathrm{P}<0.05$ & $2.91,14.6 \mathrm{df}, \mathrm{P}<0.05$ \\
\hline
\end{tabular}

A diverse assemblage of small arthropods was collected on sticky traps placed on both caged and uncaged inflorescences, with Diptera, Thysanoptera and Hemiptera being the dominant orders (Table 2). Of the dipteran families represented, Chironomidae, Ephydridae, Sciaridae and Mycetophilidae were the most abundant. There were no significant differences in sticky trap counts between caged and uncaged inflorescences for Diptera, Coleoptera, Hemiptera, Hymenoptera, Thysanoptera or other small arthropods (Table 1). However, there were some significant differences between two dipteran families, with Lonchopteridae and Dolichopodidae significantly more abundant in uncaged inflorescences than in caged inflorescences. All other dipteran families showed no significant differences between treatments $(\mathrm{P}>0.05)$ (Table 1).

\section{DISCUSSION}

Although caging inflorescences to exclude large arthropods significantly reduced the mean number of fully developed seeds per pod, and in Experiment 1, percentage seed set, 
the proportion of seeds set in caged inflorescences was still ca $33 \%$ in both experiments. Therefore the role of small arthropods in Brassica pollination cannot be discounted. However, wind pollination could have contributed significantly to the seed set, since other studies show wind as a factor in Brassica pollination (Williams 1984; Williams 1985; Korpela 1988; Walklate et al. 2004). Wind pollination alone can produce a Brassica seed crop, but exposure to large arthropods such as honeybees can significantly increase the seed yield (Free 1993, and references therein). Although it cannot be certain that the exclusion cages affected the behaviour of small arthropods and altered their pollinator effectiveness, sticky traps inside the cages demonstrated that small arthropods readily moved through the mesh and in most cases were captured at similar abundances to uncaged inflorescences. Differences between seed set in inflorescences with and without sticky traps may have been due to the effect of sticky traps on pollinator performance and abundance on and around inflorescences, or due to interactions between the sticky trap and the inflorescences themselves. A survey of small arthropods in flowering pak choi fields throughout the North and South Islands of New Zealand by Howlett et al. (2009b) demonstrated that the taxa and their relative abundance in the present experimental field (GO5) was typical of other fields. Therefore the experimental results from the present study should be applicable to other fields in New Zealand.

TABLE 2: Mean (standard error in parentheses) number per trap of arthropod orders and small dipteran families counted from sticky traps near caged and uncaged pak choi inflorescences within a flowering pak choi trial plot (treatment $n=16$ ).

\begin{tabular}{|c|c|c|c|c|c|c|c|}
\hline \multirow{2}{*}{$\begin{array}{l}\text { Order } \\
\text { Diptera }\end{array}$} & \multirow{2}{*}{$\begin{array}{l}\text { Family } \\
\text { Agromyzidae }\end{array}$} & \multicolumn{2}{|c|}{ Caged } & \multicolumn{2}{|c|}{ Uncaged } & \multirow{2}{*}{$\frac{P \text { value }}{>0.994}$} & \multirow{2}{*}{$\frac{\text { d.f. }}{14}$} \\
\hline & & 0.25 & $(0.18)$ & 0.25 & $(0.18)$ & & \\
\hline & Cecidomyiidae & 0.00 & $(0.00)$ & 0.25 & $(0.18)$ & 0.096 & 14 \\
\hline & Ceratopogonidae & 0.25 & $(0.18)$ & 0.13 & $(0.12)$ & 0.560 & 14 \\
\hline & Chironomidae & 11.25 & $(1.74)$ & 13.88 & (1.93) & 0.346 & 7 \\
\hline & Dolichopodidae & 0.75 & $(0.33)$ & 3.00 & $(0.67)$ & 0.017 & 7 \\
\hline & Drosophilidae & 2.50 & $(0.62)$ & 1.63 & $(0.50)$ & 0.309 & 7 \\
\hline & Ephydridae & 5.88 & $(0.86)$ & 4.25 & $(0.73)$ & 0.148 & 7 \\
\hline & Lonchopteridae $^{1}$ & 0.00 & $(0.00)$ & 1.25 & $(0.40)$ & $<0.001$ & 14 \\
\hline & Mycetophilidae & 4.00 & $(1.64)$ & 4.50 & $(1.74)$ & 0.840 & 7 \\
\hline & Phoridae & 1.25 & $(0.40)$ & 2.38 & $(0.54)$ & 0.092 & 7 \\
\hline & Psychodidae & 2.38 & $(0.88)$ & 3.50 & (1.07) & 0.444 & 14 \\
\hline & Scatopsidae $^{1}$ & 0.00 & $(0.00)$ & 0.25 & (1.18) & 0.096 & 7 \\
\hline & Sciaridae & 5.63 & $(0.84)$ & 6.38 & $(0.89)$ & 0.540 & 14 \\
\hline & Simuliidae $^{1}$ & 0.00 & $(0.00)$ & 0.13 & $(0.13)$ & 0.239 & 14 \\
\hline & Sphaeroceridae & 1.38 & $(0.47)$ & 1.38 & $(0.47)$ & $>0.994$ & 7 \\
\hline Total Diptera & & 35.50 & (3.94) & 43.13 & $(4.34)$ & 0.234 & 7 \\
\hline Thysanoptera & & 27.50 & $(4.67)$ & 20.75 & $(4.05)$ & 0.320 & 7 \\
\hline Hemiptera $^{1}$ & & 12.13 & $(2.95)$ & 6.75 & (1.19) & 0.164 & 14 \\
\hline Coleoptera & & 1.50 & $(0.74)$ & 0.63 & $(0.48)$ & 0.348 & 7 \\
\hline Hymenoptera & & 1.25 & $(0.43)$ & 2.50 & $(0.61)$ & 0.116 & 14 \\
\hline Lepidoptera & & 1.13 & $(0.13)$ & 0.63 & $(0.28)$ & 0.088 & 7 \\
\hline Other & & 0.88 & $(0.35)$ & 0.38 & $(0.23)$ & 0.251 & 14 \\
\hline
\end{tabular}

${ }^{1}$ Not known as pollinators of flowering plant and/or crop species. 
This study demonstrates the complexity of determining the contribution that different flower visiting arthropods and wind make to pollination in Brassica species. Brassica species are widely grown around the world as a genetically modified crop, and so has been a major focus for risk assessment studies (Timmons et al. 1996; Wilkinson et al. 2003; Walklate et al. 2004). However, many of these studies focus on the role of large arthropods (Pierre 2001; Cresswell et al. 2002; Funk et al. 2006) and wind (Timmons et al. 1995; Shaw et al. 2006) in vectoring pollen from crops, and ignore the role of small arthropods. Given that small arthropods are very abundant in Brassica fields (Howlett et al. 2009a,b) and can be carried over large distances (several kilometres) via wind currents (Lewis 1997; Pathak et al. 1999), further studies to assess their potential as vectors for long distance pollen flow are warranted.

\section{ACKNOWLEDGEMENTS}

We thank Smith Seeds Ltd for donating seed for pak choi and Stuart Armstrong for assisting with locating and planting of the pak choi trial plot. This project was funded through the New Zealand Foundation for Research, Science and Technology.

\section{REFERENCES}

Bancroft TA, Han C 1983. A note on pooling variances. Journal of the American Statistical Association 78: 981-983.

Cresswell JE, Osborne JL 2004. The effect of patch size and separation on bumblebee foraging in oilseed rape: implications for gene flow. Journal of Applied Ecology 31 (3): 539-546.

Cresswell JE, Osborne JL, Bell SA 2002. A model of pollinator-mediated gene flow between plant populations with numerical solutions for bumblebees pollinating oilseed rape. Oikos 98 (3): 375-384.

Cunningham SA, FitzGibbon F, Heard TA 2002. The future of pollinators for Australian agriculture. Australian Journal of Agricultural Research 53: 893-900.

Free JB 1993. Insect Pollination of Crops. Academic Press, London. Pp. 167-189.

Funk T, Wenzel G, Schwarz G 2006. Outcrossing frequencies and distribution of transgenic oilseed rape (Brassica napus L.) in the nearest neighbourhood. European Journal of Agronomy 24 (1): 26-34.

Howlett BG, Walker MK, Newstrom-Lloyd LE, Donovan BJ, Teulon, DAJ 2009a. Window traps and direct observations record similar arthropod flower visitor assemblages in two mass flowering crops. Journal of Applied Entomology 133 (in press), available online: http//www3.interscience.wiley.com/cgi-bin/fulltext/122246487/PDFSTART (accessed 24 April 2009).

Howlett BG, Walker MK, McCallum JA, Teulon DAJ 2009b. Small flower-visiting arthropods in New Zealand pak choi fields. New Zealand Plant Protection 62: 86-91.

Korpela S 1988. The influence of honeybee pollination on turnip rape (Brassica campestris) yield and yield components. Annales Agriculturae Fenniae 27 (4): 295-303.

Lewis T 1997. Flight and dispersal. In: Lewis T ed. Thrips as crop pests. CAB International, Wallingford, UK. Pp. 175-196.

Pathak SC, Kulshrestha V, Choubey AK, Parulekar AH 1999. Insect drift over the northern Arabian sea in early summer. Journal of Biosciences 24 (2): 233-240.

Pierre J 2001. The role of honeybees (Apis mellifera) and other insect pollinators in gene flow between oilseed rape (Brassica napus) and wild radish (Raphanus raphanistrum). Acta Horticulturae 561: 47-51.

Pierre J, Renard M 1999. Does short distance isolation reduce pollen dispersal by honey bees? Proceedings of the $10^{\text {th }}$ International Rapeseed Congress, Canberra, Australia. http://www.regional.org.au/au/gcirc/4/387.htm (retrieved 30 March 2009).

Rubin-Reyes M, Cervancia CR 1999. Floral visitors and pollination of Chinese mustard, Brassica campestris L. Philippine Journal of Science 128: 31-37. 
Shaw MW, Harwood TD, Wilkinson MJ, Elliott L 2006. Assembling spatially explicit landscape models of pollen and spore dispersal by wind for risk assessment. Proceedings of the Royal Society B-Biological Sciences 273 (1594): 1705-1713.

Timmons AM, Charters YM, Crawford JW, Burn D, Scott SE, Dubbels SJ, Wilson NJ, Robertson A, O’Brien ET, Squire GR, Wilkinson MJ 1996. Risks from transgenic crops. Nature 380 (6574): 487.

Timmons AM, O'Brien ET, Charters YM, Dubbels SJ, Wilkinson MJ 1995. Assessing the risks of wind pollination from field of genetically modified Brassica napus ssp. oleifera. Euphytica 85 (1): 417-423.

Veer V 1978. Thrips flavus (Schrank) as a pollinating agent. Indian Journal of Forestry 1: 278 .

Walklate PJ, Hunt JCR, Higson HL, Sweet JB 2004. A model of pollen-mediated gene flow for oilseed rape. Proceedings of the Royal Society of London Series B-Biological Sciences 271 (1538): 441-449.

Westerkampe C, Gottsberger G 2000. Diversity pays in crop pollination. Crop Science 40: 1209-1222.

Wilkinson MJ, Elliott LJ, Allainguillaume J, Shaw MW, Norris C, Welters R, Alexander M, Sweet J, Mason DC 2003. Hybridization between Brassica napus and B. rapa on a national scale in the United Kingdom. Science 302 (5644): 457-459.

Williams IH 1984. The concentrations of air-borne rape pollen over a crop of oil-seed rape (Brassica napus L.). Journal of Agricultural Science 103: 353-357.

Williams IH 1985. The pollination of swede rape (Brassica napus L.). Bee World 66 (1): $16-22$. 